\title{
Determination of Slow-binding HDAC Inhibitor Potency and Subclass Selectivity
}

\author{
Carlos Moreno-Yruela* and Christian A. Olsen* \\ Center for Biopharmaceuticals \& Department of Drug Design and Pharmacology, Faculty of Health and Medical Sciences, \\ University of Copenhagen DK-2100, Copenhagen, Denmark
}

KEYWORDS: Enzyme inhibitor, histone deacetylases, continuous assay, slow-binding kinetics, RGFP966

\begin{abstract}
Histone deacetylases (HDACs) 1-3 regulate chromatin structure and gene expression. These three enzymes are targets for cancer chemotherapy and are studied for the treatment of immune disorders and neurodegeneration, but there is a lack of selective pharmacological tool compounds to unravel their individual roles. Potent inhibitors of HDACs 1-3 often display slow-binding kinetics, which causes a delay in inhibitor-enzyme equilibration and may affect assay readout. Here, we compare the potency and selectivity of slow-binding inhibitors measured by discontinuous and continuous assays. We find that entinostat, a clinical candidate, inhibits HDACs $1-3$ by a two-step, slow-binding mechanism with lower potencies than previously reported. In addition, we show that RGFP966, commercialized as HDAC3-selective probe, is a slow-binding inhibitor with inhibitor constants of $57 \mathrm{nM}, 31 \mathrm{nM}$, and $13 \mathrm{nM}$ against HDACs $1-3$, respectively. These data highlight a need for thorough kinetic investigation in the development of selective HDAC probes.
\end{abstract}

Inhibition of enzymes relies on the direct interaction of the inhibitor with its target. Extending the timespan of this interaction, also termed residence time, is pursued in drug design to maximize a compound's biological impact. ${ }^{1-2}$ Slow-binding inhibitors present low dissociation rates that translate into extended residence times and, often, higher potency. ${ }^{3-6}$ However, slow-binding kinetics also cause a delay in reaching equilibrium within assays, which is not always taken into account in medicinal chemistry campaigns. ${ }^{1-2}$ Disregarding slow-binding mechanisms may lead to an underestimation of affinity against the desired target, but also against off-targets that share structural similarity such as members of the same enzyme family. Thus, understanding inhibitor kinetics is important for determining potency with accuracy and for assessing subfamily and subclass selectivity.

Histone deacetylases (HDACs) are targeted by chemotherapy, with five HDAC inhibitors in clinical use for the treatment of hematologic cancers. ${ }^{7}$ HDAC inhibitors are also undergoing clinical trials for treatment of dementia and muscular dystrophy $^{7-8}$ and are being investigated in autoimmune diseases. ${ }^{9} \mathrm{Hu}-$ mans express $11 \mathrm{Zn}^{2+}$-dependent HDACs, divided into class I (HDACs 1-3 and 8), class IIa (HDACs 4, 5, 7, and 9), class IIb (HDACs 6 and 10), and class IV (HDAC11). ${ }^{10}$ Class I HDACs, the targets of most therapies, remove $N^{\varepsilon}$-acyllysine posttranslational modifications from nuclear proteins, including histones and transcription factors, ${ }^{10-14}$ and thereby regulate gene expression. ${ }^{9}$ It is often unclear which isozymes are the relevant targets in each disease context, because there is a lack of selective tool compounds to discriminate between class I HDACs. Most inhibitors used as probes inhibit multiple classes (e.g. SAHA, 1, Figure 1), are class I-selective (e.g. romidepsin, 2), or inhibit HDACs 1-3 (e.g. entinostat, 3). ${ }^{15}$ Albeit, romidepsin (2) is the only recommended probe to study class I HDACs. ${ }^{16}$ Multiple HDAC inhibitors exhibit slow-binding kinetics, first reported

for $\alpha$-aminoanilides, ${ }^{17}$ but also found for trifluoromethylketones, ${ }^{18}$ hydroxamic acids,,${ }^{6,19}$ acylhydrazides, ${ }^{20-21}$ as well as romidepsin (2). ${ }^{19,22}$ However, kinetic data is not available for all inhibitors used as probes, such as the claimed HDAC3-selective $\alpha$-aminoanilide RGFP966 (4). ${ }^{23}$

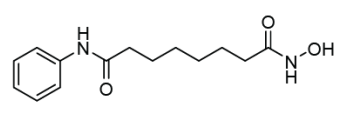

SAHA (1)

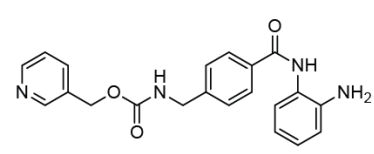

MS-275, entinostat (3)

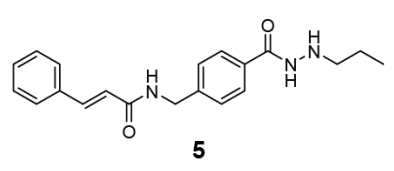

Figure 1. Structures of selected HDAC inhibitors.

Here, we determine the potency and selectivity of slow-binding HDAC1-3 inhibitors using standard end-point assays as well as discontinuous and continuous experiments that account for slow inhibitor-enzyme equilibration. We find that discontinuous assays often underestimate potency and that the calcu- 
bioRxiv preprint doi: https://doi.org/10.1101/2021.12.18.473277; this version posted December 18, 2021. The copyright holder for this preprint (which was not certified by peer review) is the author/funder, who has granted bioRxiv a license to display the preprint in perpetuity. It is made available under aCC-BY-NC-ND 4.0 International license.

lated selectivity is highly dependent on the assay format. Moreover, our data clearly shows that RGFP966 (4) is not an HDAC3-selective probe.

We selected four inhibitors for our investigations: SAHA (1), entinostat (3), RGFP966 (4), and acylhydrazide 5. ${ }^{24}$ Compounds 1 and 3 both inhibit HDACs $1-3$ with similar potency in end-point assays, while they display different kinetics of inhibition (fast- and slow-binding kinetics, respectively). ${ }^{15,}$ 17, 25 Compounds $\mathbf{4}$ and $\mathbf{5}$, on the other hand, are reported to exhibit selectivity for HDAC3 $3^{23-24}$ but their binding kinetics have not been investigated even though they are structurally similar to other known slow-binding inhibitors. ${ }^{7,21}$

First, we evaluated inhibition of HDACs 1-3 using a standard fluorescence assay based on a 7-amino-4-methylcoumarin (AMC)-coupled fluorogenic substrate. ${ }^{15,26}$ The substrate, AcLeu-Gly-Lys(Ac)-AMC, has similar Michaelis-Menten constants $\left(K_{\mathrm{M}}\right)$ for each enzyme in the low micromolar range, which allows investigation at comparable enzyme saturation conditions. ${ }^{15}$ Inhibitor and substrate were incubated with the enzyme for $30 \mathrm{~min}$ before development with a protease, providing end-
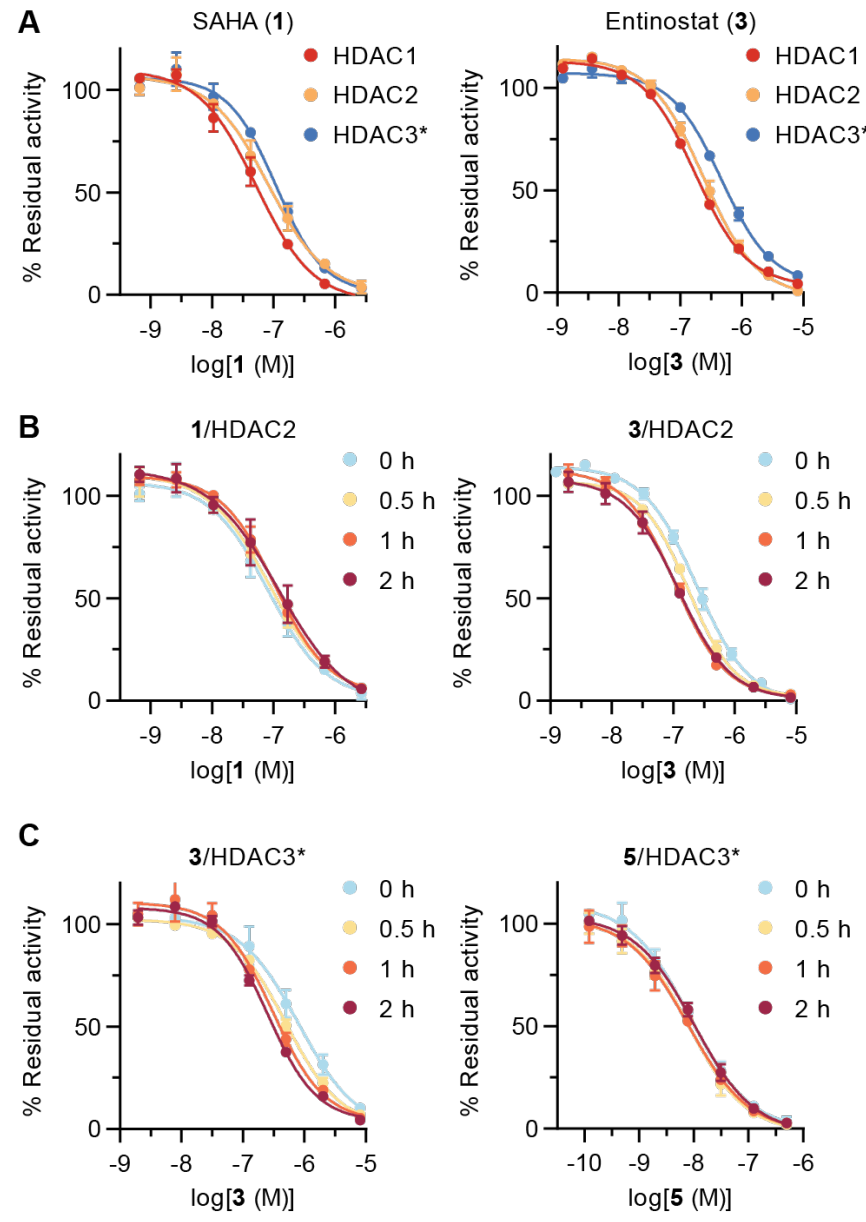

point dose-response curves (Figure 2A). SAHA (1) and entinostat (3) showed similar potency against the three enzymes, while RGFP966 (4) and compound 5 showed selectivity for HDAC3 as previously reported. However, the measured potency and selectivity of RGFP966 (4) differed significantly from the literature, with an $\mathrm{IC}_{50}$ of $514 \pm 4 \mathrm{nM}$ against HDAC3 (compared to $80 \mathrm{nM}$ ) and a selectivity ratio of $3.5 \mathrm{vs}$. HDAC2 (compared to $>180$ ) (Figure 2D). ${ }^{23}$ Data for compound 5 was in better agreement with previous reports, with a 6.1 selectivity ratio vs. HDAC1 (compared to 12.4). ${ }^{24}$

Compounds 3, 4, and 5 contain either $\alpha$-aminoanilide or acylhydrazide $\mathrm{Zn}^{2+}$-binding groups, which are prevalent in inhibitors of class I HDACs that exhibit slow-binding kinetics. ${ }^{17}$, ${ }^{20,25}$ Since slow-binding inhibitors commonly equilibrate after periods of time longer than $30 \mathrm{~min},{ }^{27}$ the performed end-point assays would not be expected to occur at steady-state. To enable equilibration, assays were next performed with pre-incubation of inhibitor and enzyme during $30 \mathrm{~min}, 1 \mathrm{~h}$ or $2 \mathrm{~h}$ before substrate addition.
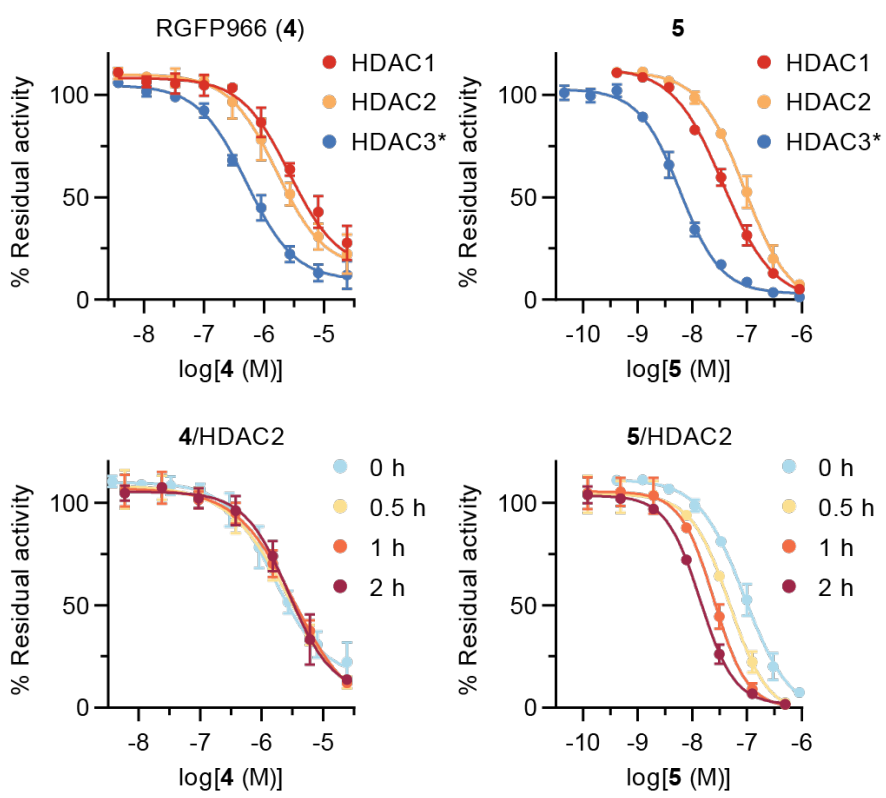

\begin{tabular}{|c|c|c|c|c|}
\hline RGFP966 (4) & HDAC1 & HDAC2 & HDAC3* & Sel. HDAC3 $^{\dagger}$ \\
\hline $\mathrm{IC}_{50}(\mu \mathrm{M})$ & $2.66 \pm 0.05$ & $1.63 \pm 0.02$ & $0.514 \pm 0.004$ & 3.5 \\
\hline $0.5 \mathrm{~h}: \mathrm{IC}_{50}(\mu \mathrm{M})$ & $3.73 \pm 0.03$ & $2.85 \pm 0.07$ & $1.24 \pm 0.01^{\ddagger}$ & 2.5 \\
\hline $1 \mathrm{~h}: \quad \mathrm{IC}_{50}(\mu \mathrm{M})$ & $4.66 \pm 0.05$ & $3.35 \pm 0.08$ & $1.06 \pm 0.01^{\ddagger}$ & 3.5 \\
\hline $\mathrm{IC}_{50}(\mu \mathrm{M})$ & $6.0 \pm 0.1$ & $2.74 \pm 0.04$ & $1.61 \pm 0.01^{ \pm}$ & 1.9 \\
\hline 5 & HDAC1 & HDAC2 & HDAC3* $^{*}$ & Sel. HDAC3 ${ }^{\dagger}$ \\
\hline $0 \mathrm{~h}: \quad \mathrm{IC}_{50}(\mathrm{nM})$ & $36.4 \pm 0.2$ & $89.9 \pm 0.7$ & $5.96 \pm 0.02$ & 6.1 \\
\hline $0.5 \mathrm{~h}: \mathrm{IC}_{50}(\mathrm{nM})$ & $11.3 \pm 0.1$ & $48.0 \pm 0.4$ & $8.2 \pm 0.1^{\ddagger}$ & 1.4 \\
\hline $1 \mathrm{~h}: \quad \mathrm{C}_{50}(\mathrm{nM})$ & $7.07 \pm 0.03$ & $24.8 \pm 0.2$ & $7.84 \pm 0.07^{\ddagger}$ & 0.9 \\
\hline $\mathrm{IC}_{50}(\mathrm{nM})$ & $4.89 \pm 0.01$ & $14.0 \pm 0.1$ & $10.2 \pm 0.1^{\ddagger}$ & 0.5 \\
\hline
\end{tabular}

Figure 2. Discontinuous inhibition of HDACs 1-3. (A) Dose-response curves measured after 30 min reaction with enzyme and substrate. (B) HDAC2 curves after pre-incubation with enzyme for $0,0.5,1$, or $2 \mathrm{~h}$, followed by addition of substrate and $30 \mathrm{~min}$ reaction. (C) HDAC3 curves of compounds 3 and $\mathbf{5}$ with and without pre-incubation, measured in buffer without reducing agents or surfactants. See Supporting Figure S1A,B for HDAC1 and additional HDAC3 curves. (D) $\mathrm{IC}_{50}$ data of compounds $\mathbf{4}$ and $\mathbf{5}$, and selectivity of HDAC3 inhibition. See Supporting Figure S1C for data of compounds 1 and 3. All data represent mean \pm SD, $n \geq 2$. *HDAC3 incubated with the deacetylase activation domain (DAD) of NCoR2. †Selectivity calculated vs. the second most inhibited enzyme (4: HDAC2, 5: HDAC1), by transforming $\mathrm{IC}_{50}$ data into $K_{\mathrm{i}}$ and calculating the ratio (see data analysis in the Supporting Information). ${ }^{\ddagger}$ Data obtained in buffer without reducing agents or surfactants (see Supporting Figure S2 and pre-incubation methods for choice of buffer). 
bioRxiv preprint doi: https://doi.org/10.1101/2021.12.18.473277; this version posted December 18, 2021. The copyright holder for this preprint (which was not certified by peer review) is the author/funder, who has granted bioRxiv a license to display the preprint in perpetuity. It is made available under aCC-BY-NC-ND 4.0 International license.

SAHA (1), a fast-on/fast-off inhibitor, inhibited HDACs 1 and 2 with similar potency regardless of pre-incubation, while entinostat (3) and compound $\mathbf{5}$ showed $49 \%$ and $84 \%$ reduction in $\mathrm{IC}_{50}$ value against $\mathrm{HDAC} 2$ after $2 \mathrm{~h}$, respectively (Figure 2B). Inhibition of HDACs 1 and 2 by RGFP966 (4) did not change, which indicates inhibitor-enzyme equilibration at the time scale 0-30 min (Figure 2B and Supporting Figure S1A). Only entinostat (3) followed a slow-binding profile for HDAC3 inhibition, with a $55 \%$ decrease in $\mathrm{IC}_{50}$ after $2 \mathrm{~h}$ pre-incubation (Figure 2C and Supporting Figure S1B).

Selectivities of compounds $\mathbf{4}$ and $\mathbf{5}$ were calculated based on each pre-incubation dataset. Compound $\mathbf{4}$ maintained similar selectivity towards HDAC3 at $30 \mathrm{~min}$ and $1 \mathrm{~h}$ pre-incubation, but lost selectivity at $2 \mathrm{~h}$ (1.9 selectivity ratio vs. HDAC2, Figure 2D). More strikingly, selectivity of compound $\mathbf{5}$ dropped from 6.1 to 1.4 after $30 \mathrm{~min}$ and further decreased at the $1 \mathrm{~h}$ and $2 \mathrm{~h}$ time-points, due to a decrease in $\mathrm{IC}_{50}$ for HDACs 1 and 2 while HDAC3 potency was maintained. Since HDAC3 experiments were carried out at $1-5 \mathrm{nM}$ enzyme concentration, this difference in behavior might be explained by compound 5 approaching stoichiometric inhibition of HDAC3 and not of HDACs 1 and 2 in the first assay without pre-incubation. Then, potential further increase in potency after pre-incubation would only be detected for HDACs 1 and 2. Nevertheless, the data highlighted the need for more thorough investigation of slowbinding inhibitor potency to assess selectivity with better accuracy.

Pre-incubation data of slow-binding inhibitors can be fit to exponential decay functions in order to calculate slow-binding kinetic and inhibitor constants. ${ }^{27}$ Here, this analysis could be performed for entinostat (3) against HDACs 2 and 3, and for compound 5 against HDACs 1 and 2, providing a rough estimate of compound potency and residence time (Supporting Figure S3). Through this analysis, entinostat (3) was calculated to have apparent inhibition constants of $\sim 73 \mathrm{nM}$ (HDAC2) and $\sim 27$ nM (HDAC3), while compound 5 exhibited even lower potency. Unfortunately, selectivity could not be recalculated due to lack of complete data sets for HDACs 1-3.

Next, we adapted the initial discontinuous assay conditions to a continuous format, by adding the protease developer directly to the reaction as previously reported. ${ }^{17}$ Protease concentration was optimized to obtain linear substrate conversion by the HDAC for 40-60 min, while ensuring deacetylation by the HDAC was the rate-limiting step (Supporting Figure S4) ${ }^{28}$ With these assay conditions in hand, we measured enzyme kinetics to determine the Michaelis-Menten constant for each of our enzyme preparations (Supporting Figure S5), and recorded enzyme activity at different concentrations of inhibitor. Fast-on/fast-off inhibitors such as SAHA (1) equilibrate rapidly to steady-state to afford linear progression curves at all inhibitor concentrations. $^{6,17-18}$ Conversely, slow-binding inhibitors lower the reaction rate over time, resulting in bending assay progression curves. Fitting the apparent first-order kinetic constant of equilibration $\left(k_{\mathrm{obs}}\right)$ to a linear or a hyperbolic function of inhibitor concentration reveals whether the inhibitor follows mechanism A or mechanism B of slow-binding kinetics, respectively (Figure 3A). In mechanism A, binding of the inhibitor to the enzyme is slow, whereas in the more common mechanism B, formation of an initial inhibitor-enzyme complex is fast while a subsequent transition to a more stable and long-lived enzymeinhibitor complex (EI*) is slower. ${ }^{27}$

Entinostat (3) afforded the characteristic bending progression curves of a slow-binding inhibitor against all three HDACs (Figure 3B). The $k_{\text {obs }}$ data fitted well to mechanism B of HDAC inhibition (Figure 3C, hyperbolic relationship), which adds further insight to the previous kinetic analysis of this compound. ${ }^{25}$,
A
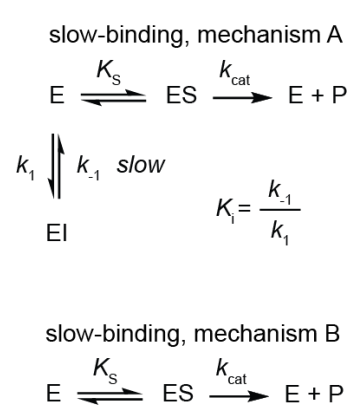

$K_{i, 1} \|$ fast

EI $\quad K_{i}=K_{i, 1} \frac{k_{-2}}{k_{2}+k_{-2}}$

$k_{2} \| k_{-2}$ slow

$\mathrm{El}^{*}$
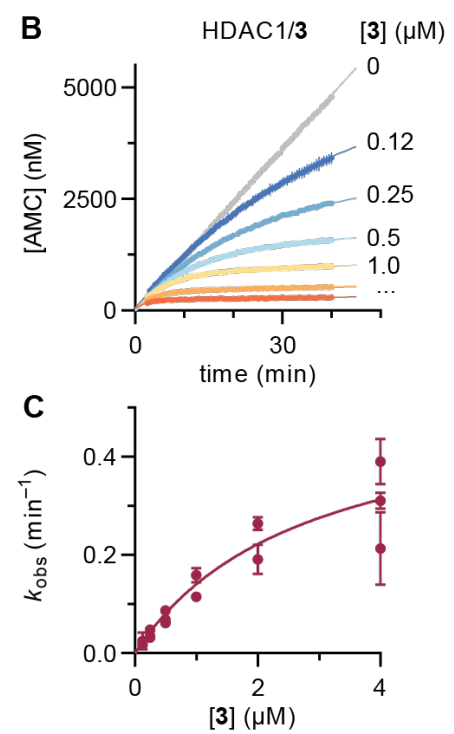
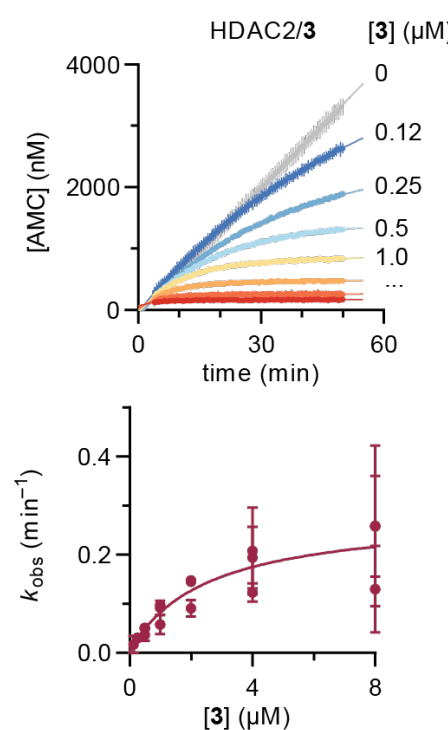
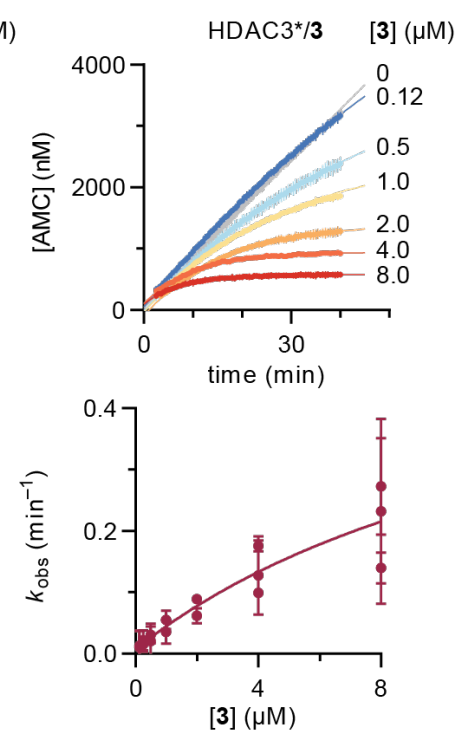

Figure 3. Models of slow-binding inhibition and continuous inhibition of HDACs 1-3 by entinostat (3). (A) Mechanism A and mechanism $\mathrm{B}$ of competitive slow-binding inhibition, and calculation of inhibitor constants $\left(K_{\mathrm{i}}\right)$ from kinetic data. (B) Continuous assay progression curves for the inhibition of HDACs $1-3$ by different concentrations of compound 3. (C) Secondary plots of the apparent first-order rate constant of equilibration $\left(k_{\mathrm{obs}}\right)$ vs. inhibitor concentration, and fitting to mechanism B of slow kinetics (see Table 1 for numerical data). Data represent mean \pm SEM of individual experiments, with each experiment performed at least twice. *HDAC3 incubated with the DAD of NCoR2. 
bioRxiv preprint doi: https://doi.org/10.1101/2021.12.18.473277; this version posted December 18, 2021. The copyright holder for this preprint (which was not certified by peer review) is the author/funder, who has granted bioRxiv a license to display the preprint in perpetuity. It is made available under aCC-BY-NC-ND 4.0 International license.

Data revealed that entinostat (3) presents a fast first binding step with equilibrium constants $\left(K_{\mathrm{i}, 1}\right)$ of $\sim 0.59 \mu \mathrm{M}$ for HDACs 1 and 2 , and $\sim 3.2 \mu \mathrm{M}$ for HDAC3, which are similar to previous estimations of potency. ${ }^{25,29}$ Taking all kinetic constants into account, the calculated potency $\left(K_{\mathrm{i}}\right)$ of entinostat (3) was $<1 \mathrm{nM}$ against HDAC1, $\sim 6 \mathrm{nM}$ against HDAC2, and $\sim 39 \mathrm{nM}$ against HDAC3 (Table 1). These values are much lower than those obtained from end-point experiments by us and others,${ }^{30}$ including HDAC2 pre-incubation assays, and also those calculated by previous fitting to mechanism A of slow binding. ${ }^{25,29}$ Our kinetic data may help explain the high potency of entinostat (3) in cellular assays, as well as its long-lasting effect due to extended enzyme dissociation half-life ( $t_{1 / 2}$, Table 1)..$^{25,30}$

Continuous assays with RGFP966 (4) revealed slow inhibition of HDACs $1-3$, which was anticipated based on its chemical structure but was not indicated in the discontinuous assays discussed above. Bending of assay progression curves was especially prominent for HDAC3 (Figure 4A), which emphasizes the higher sensitivity of continuous assays towards detecting slow-binding profiles. Inhibition of HDACs 1-3 followed mechanism $\mathrm{B}$ of slow-binding kinetics and afforded inhibitor constants of $\sim 57 \mathrm{nM}$ for HDAC1, $\sim 31 \mathrm{nM}$ for HDAC2, and $\sim 13$ nM for HDAC3 (Table 1). Based on these results, RGFP966 (4) exhibits a mere 2.4-fold selectivity towards HDAC3, which is similar to that obtained from pre-incubation $(2 \mathrm{~h}$ time-point, Figure 2D). On the other hand, the calculated potency against each enzyme is $>10$ times lower than end-point estimates. Overall, our data indicates that RGFP966 (4) is a potent inhibitor of HDACs $1-3$ with only a minor preference for HDAC3 inhibition.
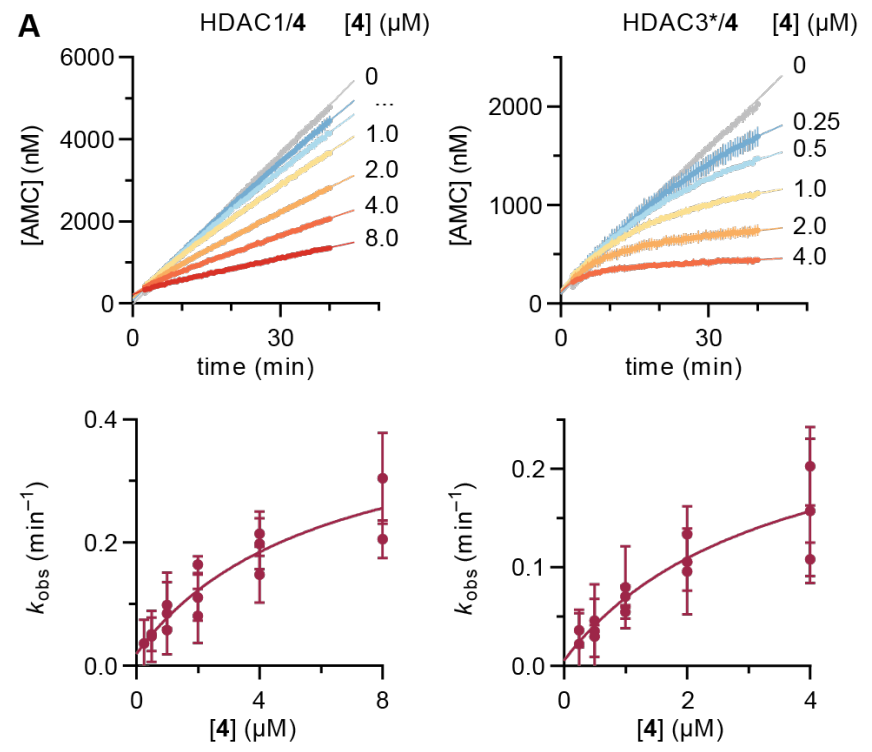

The slow-binding behavior of compound 5 against HDACs 1 and 2, which was identified by pre-incubation, was recapitulated by continuous assays. In addition, we also detected slowbinding inhibition of HDAC3 (Figure 4B).

Table 1. Calculated kinetic constants $\left(k_{\mathrm{n}}\right)$, inhibitor constants $\left(K_{\mathrm{n}}\right)$, and dissociation half-lives $\left(\mathrm{t}_{1 / 2}\right)$ of compounds $\mathbf{3}, \mathbf{4}$, and $\mathbf{5}$. Data corresponds to mechanism $\mathrm{B}$ of slow-binding kinetics, except for the inhibition of HDACs 1 and 2 by compound $\mathbf{5}$, which follows mechanism A.

\begin{tabular}{|c|c|c|c|c|}
\hline Entinostat (3) & HDAC1 & \multicolumn{2}{|l|}{ HDAC2 } & HDAC3* \\
\hline$k_{2}\left(\min ^{-1}\right)$ & $0.5 \pm 0.1$ & \multicolumn{2}{|c|}{$0.28 \pm 0.04$} & $0.6 \pm 0.5$ \\
\hline$k_{-2}\left(\min ^{-1}\right)$ & $\sim 7 \times 10^{-9}$ & \multicolumn{2}{|c|}{$\sim 3 \times 10^{-3}$} & $\sim 7 \times 10^{-3}$ \\
\hline$K_{\mathrm{i}, 1}(\mathrm{nM})$ & $590 \pm 400$ & \multicolumn{2}{|l|}{$590 \pm 340$} & $\sim 3200$ \\
\hline$K_{\mathrm{i}}(\mathrm{nM})$ & $-^{\dagger}$ & \multicolumn{2}{|l|}{$\sim 6$} & $\sim 39$ \\
\hline $\mathrm{t}_{1 / 2}(\min )$ & $>10^{5}$ & \multicolumn{2}{|l|}{$\geq 240$} & $\geq 95$ \\
\hline RGFP966 (4) & HDAC1 & \multicolumn{2}{|l|}{ HDAC2 } & $\mathrm{HDAC}^{*}$ \\
\hline$k_{2}\left(\min ^{-1}\right)$ & $0.4 \pm 0.1$ & \multicolumn{2}{|c|}{$0.38 \pm 0.03$} & $0.3 \pm 0.1$ \\
\hline$k_{-2}\left(\min ^{-1}\right)$ & $-2 \times 10^{-2}$ & \multicolumn{2}{|c|}{$\sim 7 \times 10^{-3}$} & $-5 \times 10^{-3}$ \\
\hline$K_{\mathrm{i}, 1}(\mathrm{nM})$ & $1300 \pm 1000$ & \multicolumn{2}{|c|}{$1700 \pm 400$} & $700 \pm 700$ \\
\hline$K_{\mathrm{l}}(\mathrm{nM})$ & $\sim 57$ & \multicolumn{2}{|c|}{-31} & $\sim 13$ \\
\hline$t_{1 / 2}(\min )$ & $\geq 36$ & \multicolumn{2}{|l|}{$\geq 95$} & $\geq 131$ \\
\hline 5 & HDAC1 & \multicolumn{2}{|l|}{ HDAC2 } & $\mathrm{HDAC3}^{*}$ \\
\hline$k_{1}\left(\mathrm{nM}^{-1} \cdot \mathrm{min}^{-1}\right)$ & $(7.8 \pm 0.4) \cdot 10^{-5}$ & $(5.1 \pm 0.2) \cdot 10^{-5}$ & $k_{2}\left(\min ^{-1}\right)$ & $0.78 \pm 0.08$ \\
\hline \multirow[t]{2}{*}{$k_{-1}\left(\min ^{-1}\right)$} & $(3 \pm 3) \cdot 10^{-3}$ & $(5 \pm 2) \cdot 10^{-3}$ & $k_{-2}\left(\min ^{-1}\right)$ & $\sim 4 \times 10^{-11}$ \\
\hline & & & $K_{\mathrm{i}, 1}(\mathrm{nM})$ & $25 \pm 6$ \\
\hline$K_{i}(n M)$ & $\sim 40$ & $\sim 103$ & $K_{\mathrm{I}}(\mathrm{nM})$ & $-^{\dagger}$ \\
\hline$t_{1 / 2}(\min )$ & $\sim 220$ & $\sim 130$ & $t_{1 / 2}(\min )$ & $>10^{5}$ \\
\hline
\end{tabular}

${ }^{\dagger} K_{\mathrm{i}}$ not determined due to $k_{-2}$ data fitting approaching zero. *HDAC3 incubated with the DAD domain of NCoR2.
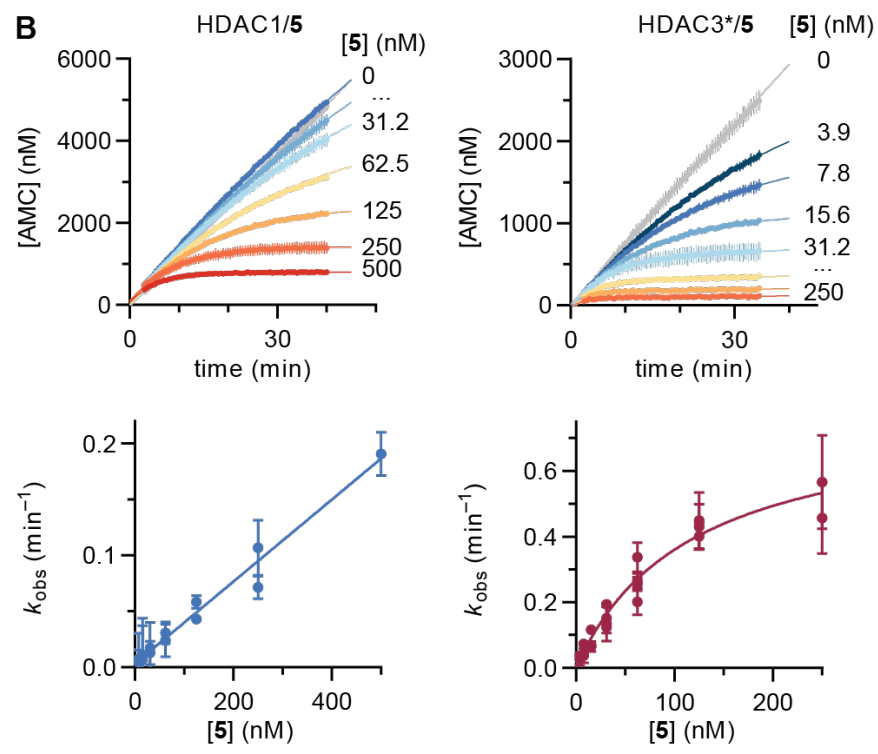

Figure 4. Continuous inhibition of HDACs 1 and 3 by RGFP966 (4) and compound 5. (A) Continuous assay progression curves (top graphs) and $k_{\mathrm{obs}}$ secondary plots (bottom graphs, mechanism B) relative to compound 4. (B) Continuous assay progression curves (top graphs) and $k_{\text {obs }}$ secondary plots (bottom graphs, HDAC1 data fitted to mechanism A and HDAC3 data fitted to mechanism B of slow binding) relative to compound 5. Data represent mean \pm SEM of individual experiments, with each experiment performed at least twice. See Supporting Figure S6 for HDAC2 data and Table 1 for numerical data. *HDAC3 incubated with the DAD of NCoR2. 
bioRxiv preprint doi: https://doi.org/10.1101/2021.12.18.473277; this version posted December 18, 2021. The copyright holder for this preprint (which was not certified by peer review) is the author/funder, who has granted bioRxiv a license to display the preprint in perpetuity. It is made available under aCC-BY-NC-ND 4.0 International license.

Interestingly, secondary plots of $k_{\mathrm{obs}}$ indicated that compound 5 follows mechanism A of HDAC1,2 inhibition, whereas it inhibits HDAC3 through mechanism B of slow binding (Figure 4B and Supporting Figure S6B). These differences in kinetic mechanism are not uncommon and were reported previously for a trifluoromethylketone inhibitor ${ }^{18}$ as well as the natural product trapoxin A. ${ }^{6}$ As a result of data fitting, the calculated $K_{\mathrm{i}}$ values of compound 5 against HDACs 1 and 2 were $\sim 40 \mathrm{nM}$ and $\sim 103 \mathrm{nM}$, respectively (Table 1), which are somewhat higher than indicated by the $\mathrm{IC}_{50}$ values obtained by end-point experiments (Figure 1D) ${ }^{24}$ Conversely, the data for inhibition of HDAC3 indicated pseudo-irreversible inhibition with very low off-rates $\left(k_{-2} \sim 0\right)$, and a first step $K_{\mathrm{i}, 1}$ of $25 \pm 6 \mathrm{nM}$. Thus, compound $\mathbf{5}$ is highly potent against HDAC1-3, with enzyme residence times of more than $2 \mathrm{~h}$ (Table 1), and with slow, tightbinding behavior of HDAC3 inhibition. Future studies will reveal whether this kinetic profile could be exploited towards selective inhibition of HDAC3 in a biological setting.

Our data underpins the need for detailed kinetic characterization of potent class I HDAC inhibitors, with particular importance when determining subclass selectivity. RGFP966 (4) is reported and commercialized as HDAC3-selective probe and has been employed in numerous studies currently associated with specific HDAC3 biology. ${ }^{23,31-33}$ Here, we show that this compound is not appropriate as an HDAC3-selective probe, which calls into question the biological functions assigned to HDAC3 based on the use of RGFP966 (4).

A recent report by Liu and coworkers identified compound 6 (Figure 1) as highly selective inhibitor of HDAC3. ${ }^{34}$ Compound 6 contains an $\alpha$-methylthiobenzamide $\mathrm{Zn}^{2+}$-binding group and exhibits slow-binding mechanism A for HDAC3 inhibition, with $K_{\mathrm{i}} \sim 24 \mathrm{nM}$ (calculated from kinetic data). ${ }^{34}$ HDACs 1 and 2 are inhibited on end-point experiments with $\mathrm{IC}_{50}$ values of $20 \mu \mathrm{M}$ and $31 \mu \mathrm{M}$, respectively, but no kinetic analyses are provided for those enzymes. Even though there is a large difference in $\mathrm{IC}_{50}$ values based on discontinuous experiments, interrogation of the inhibition of HDACs 1 and 2 in a continuous fashion might be warranted.

HDACs 1-3 form multiprotein complexes with diverse epigenetic functions ${ }^{35}$ and reports have shown that inhibitor potency and selectivity may differ between the free and the complexed HDAC forms. ${ }^{36-37}$ Therefore, future HDAC probe characterization may benefit not only from kinetic analysis against the free enzymes, but also against reconstituted complexes. One potential solution may be to measure binding to a library of HDAC complexes by time-resolved Förster resonance energy transfer (TR-FRET), as proposed recently. ${ }^{38}$ These analyses will ensure the development of robust and reproducible tool compounds for HDAC research, which are of importance for the development of epigenetic therapies against neurodegeneration and immune disorders.

In conclusion, we show that entinostat (3) is a nanomolar inhibitor of HDACs 1-3 following mechanism B of slow-binding kinetics and that acylhydrazide $\mathbf{5}$ exhibits subclass differences in kinetic behavior with a preference for inhibition of HDAC3. Importantly, we report that RGFP966 (4) is a potent slow-binding inhibitor of HDACs 1-3 and not an HDAC3-selective probe. It is our hope that these findings will assist in future experimental design towards the elucidation of class I HDAC function and subsequent drug development.

\section{ASSOCIATED CONTENT}

\section{Supporting Information}

The Supporting Information is available free of charge on the ACS Publications website.

Supporting figures, schemes and tables; supporting methods, experimental procedures, HPLC traces, and copies of NMR spectra (PDF).

\section{AUTHOR INFORMATION}

\section{Corresponding Authors}

* E-mail: carlos.myruela@sund.ku.dk (C.M.-Y.)

* E-mail: cao@sund.ku.dk (C.A.O.)

\section{ORCID}

Carlos Moreno-Yruela: 0000-0003-2450-6519

Christian Adam Olsen: 0000-0002-2953-8942

Notes

The authors declare no competing financial interests.

\section{ACKNOWLEDGMENT}

This project has received funding from the European Research Council (ERC) under the European Union's Horizon 2020 Research and Innovation Programme (grant agreement number CoG-725172-SIRFUNCT; C.A.O.).

\section{ABBREVIATIONS}

$\mathrm{DAD}$, deacetylase activation domain; HDAC, histone deacetylase; $k_{\text {obs }}$, apparent first-order rate constant of equilibration; NCoR2, nuclear receptor co-repressor 2.

\section{REFERENCES}

1. Copeland, R. A.; Pompliano, D. L.; Meek, T. D., Drug-target residence time and its implications for lead optimization. Nat Rev Drug Discov 2006, 5 (9), 730-739.

2. Holdgate, G. A.; Meek, T. D.; Grimley, R. L., Mechanistic enzymology in drug discovery: a fresh perspective. Nat Rev Drug Discov 2018, 17 (2), 115-132.

3. Basavapathruni, A.; Jin, L.; Daigle, S. R.; Majer, C. R.; Therkelsen, C. A.; Wigle, T. J.; Kuntz, K. W.; Chesworth, R.; Pollock, R. M.; Scott, M. P.; Moyer, M. P.; Richon, V. M.; Copeland, R. A.; Olhava, E. J., Conformational adaptation drives potent, selective and durable inhibition of the human protein methyltransferase DOT1L. Chem Biol Drug Des 2012, 80 (6), 971-980.

4. Chang, A.; Schiebel, J.; Yu, W.; Bommineni, G. R.; Pan, P.; Baxter, M. V.; Khanna, A.; Sotriffer, C. A.; Kisker, C.; Tonge, P. J., Rational optimization of drug-target residence time: insights from inhibitor binding to the Staphylococcus aureus FabI enzyme-product complex. Biochemistry 2013, 52 (24), 4217-4228.

5. Copeland, R. A., The drug-target residence time model: a 10year retrospective. Nat Rev Drug Discov 2016, 15 (2), 87-95.

6. Moreno-Yruela, C.; Fass, D. M.; Cheng, C.; Herz, J.; Olsen, C. A.; Haggarty, S. J., Kinetic Tuning of HDAC Inhibitors Affords Potent Inducers of Progranulin Expression. ACS Chem Neurosci 2019, 10 (8), 3769-3777.

7. Ho, T. C. S.; Chan, A. H. Y.; Ganesan, A., Thirty Years of HDAC Inhibitors: 2020 Insight and Hindsight. $J$ Med Chem 2020, 63 (21), 12460-12484.

8. Kristensen, H. M. E.; Madsen, A. S.; Olsen, C. A., Inhibitors of the Zinc dependent Histone Deacetylases. In Epigenetic Drug Discovery, Sippl, W.; Jung, M., Eds. Wiley-VCH: 2019; Vol. 74, pp 155-184. 
bioRxiv preprint doi: https://doi.org/10.1101/2021.12.18.473277; this version posted December 18, 2021. The copyright holder for this preprint (which was not certified by peer review) is the author/funder, who has granted bioRxiv a license to display the preprint in perpetuity. It is made available under aCC-BY-NC-ND 4.0 International license.

9. Falkenberg, K. J.; Johnstone, R. W., Histone deacetylases and their inhibitors in cancer, neurological diseases and immune disorders. Nat Rev Drug Discov 2014, 13 (9), 673-691.

10. Yang, X. J.; Seto, E., The Rpd3/Hdal family of lysine deacetylases: from bacteria and yeast to mice and men. Nat Rev Mol Cell Biol 2008, 9 (3), 206-218.

11. Madsen, A. S.; Olsen, C. A., Profiling of Substrates for Zincdependent Lysine Deacylase Enzymes: HDAC3 Exhibits Decrotonylase Activity In Vitro. Angew Chem 2012, 124 (36), 9217-9221.

12. Wei, W.; Liu, X.; Chen, J.; Gao, S.; Lu, L.; Zhang, H.; Ding, G.; Wang, Z.; Chen, Z.; Shi, T.; Li, J.; Yu, J.; Wong, J., Class I histone deacetylases are major histone decrotonylases: evidence for critical and broad function of histone crotonylation in transcription. Cell Res 2017, 27 (7), 898-915.

13. Huang, H.; Zhang, D.; Weng, Y.; Delaney, K.; Tang, Z.; Yan, C.; Qi, S.; Peng, C.; Cole, P. A.; Roeder, R. G.; Zhao, Y., The regulatory enzymes and protein substrates for the lysine betahydroxybutyrylation pathway. Sci Adv 2021, 7 (9), eabe2771.

14. Moreno-Yruela, C.; Zhang, D.; Wei, W.; Bæk, M.; Liu, W.; Gao, J.; Danková, D.; Nielsen, A. L.; Bolding, J. E.; Yang, L.; Jameson, S. T.; Wong, J.; Olsen, C. A.; Zhao, Y., Class I Histone Deacetylases (HDAC1-3) are Histone Lysine Delactylases. Sci Adv 2022, 10.1126/sciadv.abi6696.

15. Bradner, J. E.; West, N.; Grachan, M. L.; Greenberg, E. F.; Haggarty, S. J.; Warnow, T.; Mazitschek, R., Chemical phylogenetics of histone deacetylases. Nat Chem Biol 2010, 6 (3), 238-243.

16. The inhibitors apicidin, entinostat, SAHA, trichostatin A, and panobinostat are rated "historical compounds" and no longer recommended at chemicalprobes.org (accessed November 2021).

17. Chou, C. J.; Herman, D.; Gottesfeld, J. M., Pimelic Diphenylamide 106 Is a Slow, Tight-binding Inhibitor of Class I Histone Deacetylases. J Biol Chem 2008, 283 (51), 3540235409.

18. Madsen, A. S.; Olsen, C. A., A potent trifluoromethyl ketone histone deacetylase inhibitor exhibits class-dependent mechanism of action. MedChem Comm 2016, 7 (3), 464-470.

19. Kitir, B. 1.; Maolanon, A. R.; Ohm, R. G.; Colaço, A. R.; Fristrup, P.; Madsen, A. S.; Olsen, C. A., Chemical editing of macrocyclic natural products and kinetic profiling reveal slow, tight-binding histone deacetylase inhibitors with picomolar affinities. Biochemistry 2017, 56 (38), 5134-5146.

20. Wang, Y.; Stowe, R. L.; Pinello, C. E.; Tian, G.; Madoux, F.; Li, D.; Zhao, L. Y.; Li, J. L.; Wang, Y.; Wang, Y.; Ma, H.; Hodder, P.; Roush, W. R.; Liao, D., Identification of histone deacetylase inhibitors with benzoylhydrazide scaffold that selectively inhibit class I histone deacetylases. Chem Biol 2015, 22 (2), 273-284.

21. Li, X.; Peterson, Y. K.; Inks, E. S.; Himes, R. A.; Li, J.; Zhang, Y.; Kong, X.; Chou, C. J., Class I HDAC Inhibitors Display Different Antitumor Mechanism in Leukemia and Prostatic Cancer Cells Depending on Their p53 Status. J Med Chem 2018, 61 (6), 2589-2603.

22. Robers, M. B.; Dart, M. L.; Woodroofe, C. C.; Zimprich, C. A.; Kirkland, T. A.; Machleidt, T.; Kupcho, K. R.; Levin, S.; Hartnett, J. R.; Zimmerman, K.; Niles, A. L.; Ohana, R. F.; Daniels, D. L.; Slater, M.; Wood, M. G.; Cong, M.; Cheng, Y. Q.; Wood, K. V., Target engagement and drug residence time can be observed in living cells with BRET. Nat Commun 2015, 6, 10091.

23. Malvaez, M.; McQuown, S. C.; Rogge, G. A.; Astarabadi, M.; Jacques, V.; Carreiro, S.; Rusche, J. R.; Wood, M. A., HDAC3selective inhibitor enhances extinction of cocaine-seeking behavior in a persistent manner. Proc Natl Acad Sci U S A 2013, 110 (7), 2647-2652.
24. McClure, J. J.; Zhang, C.; Inks, E. S.; Peterson, Y. K.; Li, J.; Chou, C. J., Development of Allosteric Hydrazide-Containing Class I Histone Deacetylase Inhibitors for Use in Acute Myeloid Leukemia. J Med Chem 2016, 59 (21), 9942-9959.

25. Lauffer, B. E.; Mintzer, R.; Fong, R.; Mukund, S.; Tam, C.; Zilberleyb, I.; Flicke, B.; Ritscher, A.; Fedorowicz, G.; Vallero, R.; Ortwine, D. F.; Gunzner, J.; Modrusan, Z.; Neumann, L.; Koth, C. M.; Lupardus, P. J.; Kaminker, J. S.; Heise, C. E.; Steiner, P., Histone deacetylase (HDAC) inhibitor kinetic rate constants correlate with cellular histone acetylation but not transcription and cell viability. $J$ Biol Chem 2013, 288, 2692626943.

26. Wegener, D.; Hildmann, C.; Riester, D.; Schwienhorst, A., Improved fluorogenic histone deacetylase assay for highthroughput-screening applications. Anal Biochem 2003, 321 (2), 202-208.

27. Copeland, R. A., Slow binding inhibitors. In Evaluation of enzyme inhibitors in drug discovery, Wiley-Interscience: 2005; Vol. 46, pp 141-177.

28. Moreno-Yruela, C.; Olsen, C. A., High-throughput screening of histone deacetylases and determination of kinetic parameters using fluorogenic assays. STAR Protoc 2021, 2 (1), 100313.

29. Becher, I.; Dittmann, A.; Savitski, M. M.; Hopf, C.; Drewes, G.; Bantscheff, M., Chemoproteomics reveals time-dependent binding of histone deacetylase inhibitors to endogenous repressor complexes. ACS Chem Biol 2014, 9 (8), 1736-1746.

30. Hu, E.; Dul, E.; Sung, C. M.; Chen, Z.; Kirkpatrick, R.; Zhang, G. F.; Johanson, K.; Liu, R.; Lago, A.; Hofmann, G.; Macarron, R.; de los Frailes, M.; Perez, P.; Krawiec, J.; Winkler, J.; Jaye, M., Identification of novel isoform-selective inhibitors within class I histone deacetylases. J Pharmacol Exp Ther 2003, 307 (2), 720-728.

31. Wells, C. E.; Bhaskara, S.; Stengel, K. R.; Zhao, Y.; Sirbu, B.; Chagot, B.; Cortez, D.; Khabele, D.; Chazin, W. J.; Cooper, A.; Jacques, V.; Rusche, J.; Eischen, C. M.; McGirt, L. Y.; Hiebert, S. W., Inhibition of histone deacetylase 3 causes replication stress in cutaneous T cell lymphoma. PLoS One 2013, 8 (7), e68915.

32. Leus, N. G.; van der Wouden, P. E.; van den Bosch, T.; Hooghiemstra, W. T. R.; Ourailidou, M. E.; Kistemaker, L. E.; Bischoff, R.; Gosens, R.; Haisma, H. J.; Dekker, F. J., HDAC 3-selective inhibitor RGFP966 demonstrates antiinflammatory properties in RAW 264.7 macrophages and mouse precision-cut lung slices by attenuating NF-kappaB p65 transcriptional activity. Biochem Pharmacol 2016, 108, 58-74.

33. Janczura, K. J.; Volmar, C. H.; Sartor, G. C.; Rao, S. J.; Ricciardi, N. R.; Lambert, G.; Brothers, S. P.; Wahlestedt, C., Inhibition of HDAC3 reverses Alzheimer's disease-related pathologies in vitro and in the $3 \times$ Tg-AD mouse model. Proc Natl Acad Sci U S A 2018, 115 (47), E11148-E11157.

34. Liu, J.; Yu, Y.; Kelly, J.; Sha, D.; Alhassan, A. B.; Yu, W.; Maletic, M. M.; Duffy, J. L.; Klein, D. J.; Holloway, M. K.; Carroll, S.; Howell, B. J.; Barnard, R. J. O.; Wolkenberg, S.; Kozlowski, J. A., Discovery of Highly Selective and Potent HDAC3 Inhibitors Based on a 2-Substituted Benzamide Zinc Binding Group. ACS Med Chem Lett 2020, 11 (12), 2476-2483.

35. Millard, C. J.; Watson, P. J.; Fairall, L.; Schwabe, J. W. R., Targeting Class I Histone Deacetylases in a "Complex" Environment. Trends Pharmacol Sci 2017, 38 (4), 363-377.

36. Bantscheff, M.; Hopf, C.; Savitski, M. M.; Dittmann, A.; Grandi, P.; Michon, A. M.; Schlegl, J.; Abraham, Y.; Becher, I.; Bergamini, G.; Boesche, M.; Delling, M.; Dumpelfeld, B.; Eberhard, D.; Huthmacher, C.; Mathieson, T.; Poeckel, D.; Reader, V.; Strunk, K.; Sweetman, G.; Kruse, U.; Neubauer, G.; Ramsden, N. G.; Drewes, G., Chemoproteomics profiling of HDAC inhibitors reveals selective targeting of HDAC complexes. Nat Biotechnol 2011, 29 (3), 255-265. 
bioRxiv preprint doi: https://doi.org/10.1101/2021.12.18.473277; this version posted December 18,2021 . The copyright holder for this preprint (which was not certified by peer review) is the author/funder, who has granted bioRxiv a license to display the preprint in perpetuity. It is made available under aCC-BY-NC-ND 4.0 International license.

37. Fuller, N. O.; Pirone, A.; Lynch, B. A.; Hewitt, M. C.; Quinton, M. S.; McKee, T. D.; Ivarsson, M., CoREST ComplexSelective Histone Deacetylase Inhibitors Show Prosynaptic Effects and an Improved Safety Profile To Enable Treatment of Synaptopathies. ACS Chem Neurosci 2019, 10 (3), 17291743.

38. Payne, N. C.; Mazitschek, R., Resolving the Deceptive Isoform and Complex Selectivity of HDAC1/2 Inhibitors. preprint 2021, $10.2139 /$ ssrn.3960267.

Table of Contents artwork:

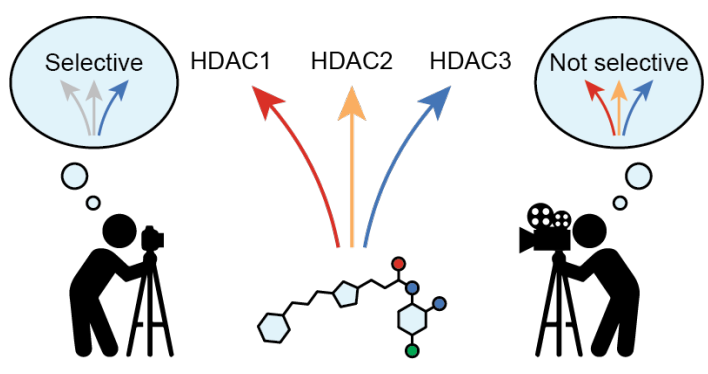

